\title{
Server Clustering in Cloud Computing Using Proxmox Based High Availability Method
}

\author{
L. LApriliana ${ }^{1}$, D. Kucuk ${ }^{2}$, N.N Diana ${ }^{3}$
}

\section{Program Studi Teknik Informatika, Fakultas Teknologi Komunikasi dan Informatika, Universitas Nasional}

\begin{abstract}
Cloud Computing technology Service and data stored on machine, the server this makes important factor engine server as a supporting service availability. More and more users are accessing the service will result in engine performance server load becomes heavier and less than optimal, because the service must work continuously to provide data that can be accessed anytime by the user via the network connected. Server hardware has a performance period. Likewise with software that may crash. With functionality server which provides services to the client, the server is required to have level of availability. A high this enables the engine server to experience downtime. Server machine must also be turned off for maintenance purposes. The purpose of this study is build Clustering Server to work together as a single system which over the virtual environment. This is a solution to overcome these problems. In this study researcher use a server virtualization proxmox, FreeNAS is a NAS server and DRBD to support high availability of services in the sphere of $H A$, data synchronization in a High Availability to perform mirroring another system machine. With the implementation of the method of $H A$ and synchronization DRBD and NFS (Network File System) on a system cluster obtained results average migration time on node1 towards node 2 reach 9.7(s), 3.7(s) for node2 towards node3, and 3(s) on node3 towards node1. Also obtained downtime less amounting
\end{abstract}

$0.58 \mathrm{~ms}$ on node1, on node $20.02 \mathrm{~ms}$, and $0.02 \mathrm{~ms}$ on node3.

Intisari- Layanan dan data teknologi Cloud Computing tersimpan pada server, hal ini menjadikan faktor pentingnya server sebagai pendukung ketersediaan layanan. Semakin banyak pengguna yang mengakses layanan tersebut ak an mengakibatkan beban kinerja mesin server menjadi lebih berat dan kurang optimal, karena layanan harus bekerja menyediakan data terus menerus yang dapat diakses kapanpun oleh penggunanya melalui jaringan terkoneksi. Perangkat keras server memiliki masa performa kinerja. Hal serupa dengan perangkat lunak yang dapat mengalami crash. Dengan fungsi server yang memberikan layanan kepada client, server dituntut untuk memiliki tingkat availability yang tinggi. Hal tersebut memungkinkan mesin server mengalami down. Server juga harus dimatikan untuk keperluan pemeliharaan. Penelitian bertujuan ini membangun Clustering Server yang dapat bekerja bersama yang seolah merupakan sistem tunggal diatas lingkungan virtual. Hal ini merupakan solusi untuk mengatasi permasalahan tersebut. Pada penelitian ini penulis menggunakan server vir tualisasi proxmox, FreeNAS sebagai server NAS dan DRBD untuk pendukung ketersediaan layanan tinggi dalam lingkup HA, sinkronisasi data dalam High Availability (HA) yang dapat melakukan mirroring sistem kemesin lain. Dengan diterapk annya metode HA dan sinkronasi DRBD serta penggunaan NFS (Network File System) pada sistem cluster didapatkan hasil rata-rata waktu migrasi sebesar 9.7(s) pada node1 menuju node2, 3.7(s) node2 menuju node3, dan 3(s) pada node3 menuju node1. Didaptkan juga waktu downtime yang lebih sedikit yaitu sebesar 0.58 ms pada node1, $0.02 \mathrm{~ms}$ pada node2, dan $0.02 \mathrm{~ms}$ pada node3.

Kata Kunci-Klaster, High Availability, proxmox VE, server, virtualisasi

\section{PENDAHULUAN}

Cloud Computing merupakan komputasi dimana kapabilitas terkait teknologi informasi disajikan sebagai suatu layanan (as a service), sehingga pengguna dapat mengaksesnya melalui internet tanpa mengetahui apa yang ada didalamnya beserta kendali terhadap infrastruktur teknologi yang membantunya.

Cloud computing mengacu pada paradigma berorientasi layanan di mana penyedia layanan menawarkan komputasi awan mengacu pada paradigma berorientasi layanan di mana penyedia layanan menawarkan komputasi sumber daya seperti perangkat keras, perangkat lunak, penyimpanan dan platform sebagai layanan sesuai dengan tuntutan pengguna[8]. Salah satu kendali yang berada didalam cloud computing adalah mesin server. Layanan harus dapat diakses kapanpun client ingin mengaksesnya, sedangkan server yang menampung data pada cloud harus dilakukan maintenance dan upgrade Oleh karena itu, diperlukannya clustering server yang bertujuan untuk mengurangi beban kerjaserver.

Untuk meningkatkan kualitas kerja server dibutuhkannya solusi Ketika terjadi masalah dalam satu node maka mesin virtual didalamnya akan berpindah ke node lain untuk memninimalkan gangguan pada layanan yang di akses client. Layanan-layanan server dijalankan pada mesin-mesin server virtual di dalam mesin server fisik. Jumlah layanan yang banyak, data-data penting, dan tingkat ketergantungan kinerja dari perusahaan, instansi, atau organisasi yang tinggi terhadap layanan server membuat server harus dapat melayani secara terus menerus[1].

High availability server digunakan untuk mengantisipasi kegagalan atau kerusakan devices pada komputer server yang dapat mengganggu kinerja sistem jaringan[3]. Downtime adalah waktu (period of time) dimana sistem tidak dapat digunakan untuk menjalankan fungsinya sesuai yang diharapkan. Downtime sangat berpengaruh pada nilai availability dari suatu equipment [2]. 
Penelitian bertujuan untuk mengoptimalkan kerja server dengan digunakannya sistem clustering pada server serta digunakannya metode high availability guna meningkatkan dan membantu kinerja mesin server agar beban yang dikerjakan mesin server tidak terlalu berat

\section{PENELITIAN TERKAIT}

Masalah pada penelitian sebelumnya didapatkan bahwa DRBD tidak berfungsi seperti yang diharapkan. DRBD hanya bisa melakukan replikasi data hanya untuk 2 node. Proses replikasi hanya dapat dilakukan dengan menggunakan 2 node sementara adanya node 3 hanya sebagai cadangan (Backup). Sehingga fungsi replikasi $\mathrm{t}$ idak berjalan sebagaimana mestinya pada node ke-3[7].

Untuk meningkatkan dan mengoptimalkan kinerja server perlu dibangun clustering server agar ketika salah satu mesin server sedang mengalami gangguan ataupun sedang dilakukan pemeliharaan, layanan cloud tetap bisa diakses tanpa harus dilakukan pemberhentian layanan sementara. Walau sedang dilakukan maintenance pada server, pengguna dapat melakukan proses akses semua data yang ada di cloud dalam waktu, ruang dan tempat yang tidak dibatasi. Dari hasil uji coba pemanfaatan metode high availability yang didukung dengan bantuan distributed replicated block device didapatkan hasil downtime yang lebih rendah dan waktu migrasi yang lebih cepat.

Pada penelitian ini dilakukan perbandingan antara HA dengan bantuan DRBD pada node2 dan node3 dan HA tanpa bantuan DRBD pada node1. Pada downtime yang didukung metode HA dengan bantuan distributed replicated block device didapatkan nilai $0.02 \mathrm{~ms}$ pada node2, dan $0.02 \mathrm{~ms}$ pada node3. Pada uji coba untuk waktu migrasi yang didukung oleh metode HA dengan bantuan distributed replicated block device didapatkan hasil rata-rata 3.7(s) node2 menuju node3, dan 3(s) pada node3 menuju node1. Sedangkan dari hasil uji coba downtime pada node 1 yang tidak menggunakan bantuan DRBD didapatkan nilai $0.58 \mathrm{~ms}$ dan untuk waktu migrasi didapatkan nilai rata-rata 9.7(s) pada node1 menuju node2.

Kekurangan dari virtualisasi server adalah mengumpulnya semua service pada 1 mesin, sehingga apabila secara fisik mesin tersebut rusak atau error maka akan semua sistem yang berjalan diatasnya akan fail. Hal ini dapat diatasi dengan membuat mekanisme redundant server atau fail over server sebagai cadangan[5].

Waktu yang dibutuhkan pada saat migrasi server, dikarenakan node bermasalah, atau dikondisikan ada node yang mengalami kegagalan sistem, adalah : 1 menit 39 detik[6]. Pada perbandingan tabel penelitian sebelumnya didapatkan dalam 3 kali pengujian waktu migrasi melalu server 1 ke server 2 pengujian 1 didapatkan jumlah migrasi sebesar 7(s), pengujian ke-2 didapatkan waktu migrasi sebesar 13(s) dan pengujian ke-3 didapatkan waktu migrasi 11(s) yang total rata-ratanya adalah 10.3 second. Lalu pada server 2 menuju ke server 1 didapatkan waktu migrasi pada pengujian 1 sebesar 9(s), pengujian ke-2 sebesar 11(s) dan pengujian ke3 sebesar 9(s), dengan total rata-rata sebesar 10.3 second. Salah satu downtime yang diambil dari jurnal acuan terdapat waktu downtime sebesar $0.7(\mathrm{~s})$ pada server 1 menuju server 2 dan $0.7(\mathrm{~s})$ dari server 2 ke server 1[4].

Berdasarkan beberapa perbandingan migrasi selanjutnya terdapat hasil pengujian sebesar 51(s) pada pengujian 1, 23(s) pada penujian ke-2 dan 42(s) pada pengujian ke-3 pada server
1, pada server 2 terdapat hasil migrasi sebesar 56(s) pada pengujian 1, 24(s) pada pengujian ke-2 dan 44(s) pada pengujian ke-3. Server 3 mendapatkan waktu migrasi sebesar 58(s) pada pengujian 1, 23(s) pada pengujian ke-2 dan 40(s) pada pengujian ke-3. Hasil downtime sebesar 1.3(s) pada server $1,0.2(\mathrm{~s})$ pada server 2 dan $0.4(\mathrm{~s})$ pada server $3[1]$.

\section{METODE PENELITIAN}

\section{Alur Perancangan}

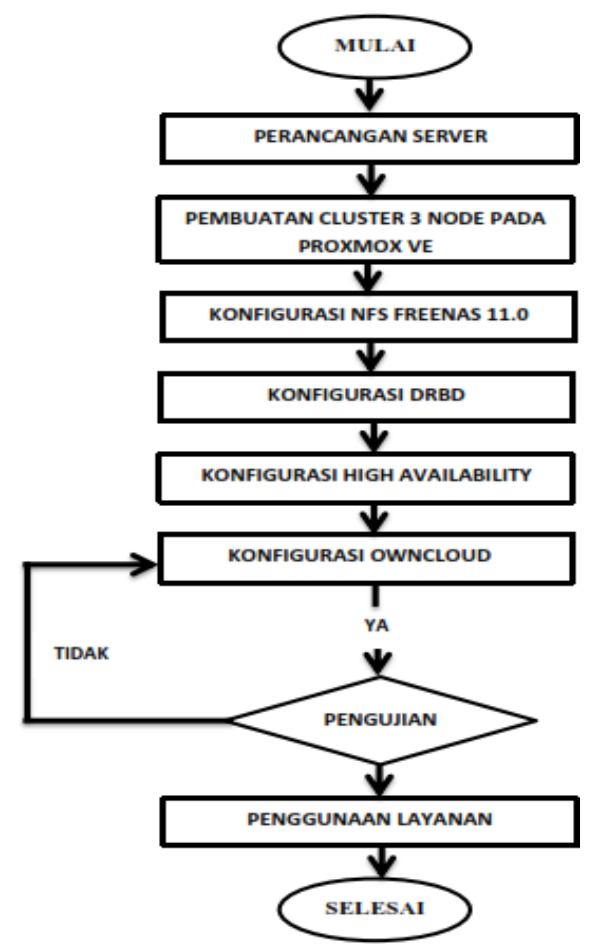

Gambar 1 Flowchart Perancangan

Pada Ga mbar 1 menjelaskan perancangan sistem clustering menggunakan metode High Availability. Tahapan pertama dilakukan penginstalan proxmox VE, yang akan digunakan sebagai platform dalam pembuatan clustering server. Perancangan dalam sistem in i menggunakan 3 node yang akan dijadikan sebuah cluster. penulis menginstal freenas untuk penggabungan storage pada cluster proxmox dan menerapkan konfigurasi DRBD untuk mirroring pada setiap node dalam lingkungan $\mathrm{HA}$ guna menghindari gangguan layanan. Didalam proxmox penulis menginstal owncloud dalam virtual mesin. Owncloud telah dilakukan konfigurasi agar client dapat mengakses layanan pada cloud.

\section{Desain Topologi}

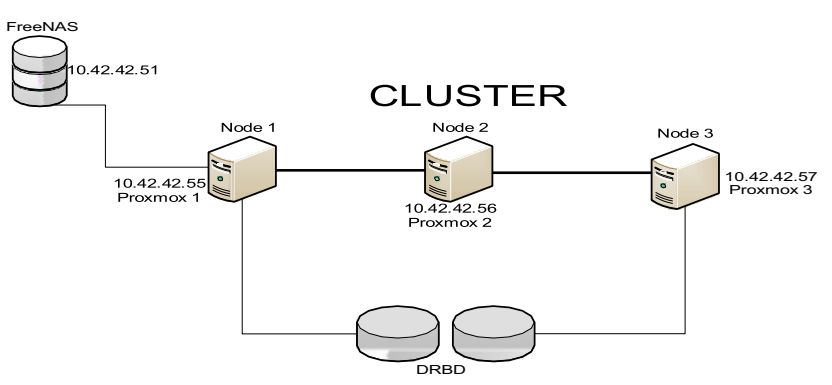

Gambar 2 Desain Topologi 
Dari desain topologi diatas menjelaskan sebuah server virtual yang masing-masing memiliki ip berbeda yang sudah di konfigurasi menjadi node-node yang sudah ter cluster dengan layanan tinggi dapat diakses client melalui layanan cloud computing.

\section{Konfigurasi Sistem Cluster}

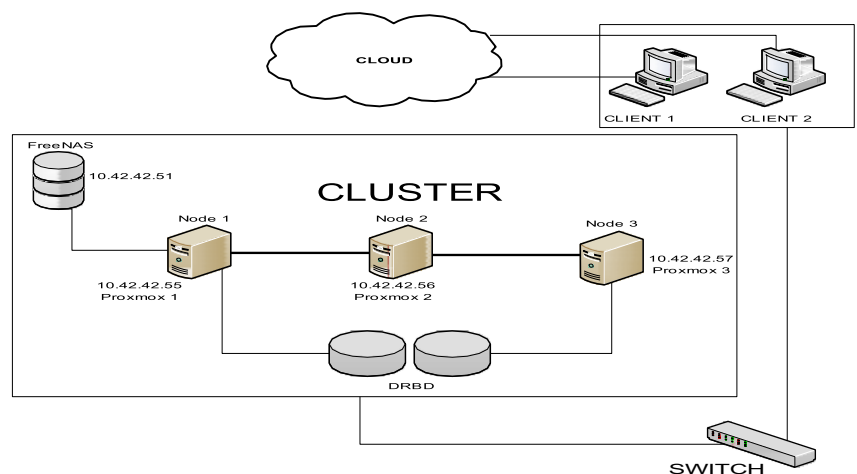

Gambar 3 Konfigurasi Cluster

Gambar diatas menggambarkan proses pembentukan 3 node menjadi cluster dengan bantuan DRBD untuk kestabilan layanan HA dan menggunakan storage freenas.

Tabel 1

Perangkat Keras

\begin{tabular}{|l|l|l|}
\hline No & Hardware & Spesifikasi Hardwere \\
\hline 1 & PC Proxmox & Intel Core i7-4500U CPU \\
& $1,2,3$ & $@ 1.80 \mathrm{GHz}$ (4 CPUs), 2.4GHz \\
& & Windows 8.1 Pro 64-bit \\
\cline { 3 - 3 } & & Memory 4096MB RAM \\
\hline \multirow{2}{*}{2} & \multirow{2}{*}{ PC NAS } & Hardisk 1TB \\
\hline \multirow{2}{*}{} & & Intel Core i5 \\
\hline & & Windows 7 Ultimate 64-bit \\
\hline & & Memory 4GB RAM \\
\hline & & Hardisk 500GB \\
\hline
\end{tabular}

Tabel 2

Perangkat Lunak

\begin{tabular}{|l|l|l|}
\hline No & Software & Spesifikasi \\
\hline 1 & $\begin{array}{l}\text { Proxmox VE } \\
5.0\end{array}$ & $\begin{array}{l}\text { Untuk membuat virtualisasi } \\
\text { server cluster }\end{array}$ \\
\hline 2 & FreeNAS 11.0 & $\begin{array}{l}\text { Untuk Server Network Attached } \\
\text { Storage (NAS) }\end{array}$ \\
\hline 3 & Owncloud & $\begin{array}{l}\text { Sebagai Layanan yang akan } \\
\text { diakses Client }\end{array}$ \\
\hline 4 & Fping & Sebagai uji downtime \\
\hline
\end{tabular}

\section{HASIL DAN PEMBAHASAN}

Pada tahapan pembuatan cluster seperti gambar dibawah menjelaskan:

\#pvecm create mycluster, sebagai nama dari cluster yang dibuat.

\#pvecm add, merupakan penambahan node cluster. \#pvecm status, merupakan pengecekan status apakah server telah tergabung.

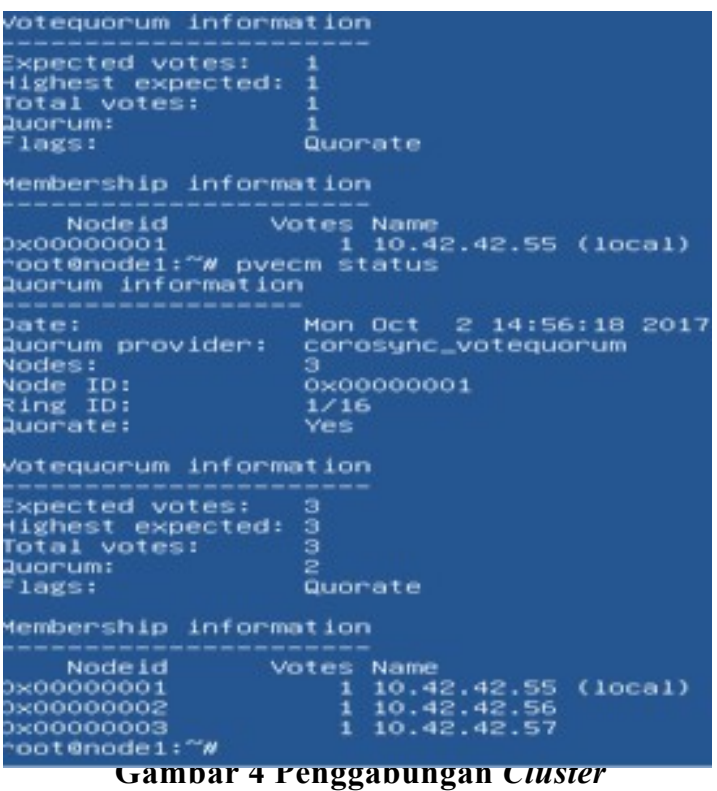

Menjadikan nodel sebagai server utama. Lalu gabungkan node 2 dan node 3 untuk dijadikan cluster. lakukan pengecekan dengan $P I N G$ dan pvecm status untuk mengetahui semua node yang sudah terdaftar pada cluster.

\#apt-get install drba8-utils, proses instal distributed duplicated block device.

\#fdisk /dev/sdb, untuk mempartisi new virtual disk untuk drbd.

\#nano etc/drbd.d/global common.conf, untuk membuat konfigurasi DRBD global dan umum.

\#nano / etc/drbd.d/ro.res, satu bagian sumber daya masing masing.

\# resource ro, utnuk memanggil fungsi drbd.

\#protocol C, sinkronasi

pvcreate /dev/drbdo (membuat physical volume disk)

\#address 10.42.42.55:7788, sinkronasi standar port DRBD

\#drbdadm--overwrite-data-of-peer primary ro, cek status service dan hasilnya akan tersinkronasi.

\# watch cat /proc/drbd, proses sinkronasi tunggu hingga $100 \%$.

\# service drbd start, memulai DRBD.

\#service drbd restart, mengulang kembali DRBD.

Gambar 5 ditunjukkan bagaimana cara menginstal DRBD (Distributed Replicated Block Device) sebagai backup data pada server disaat salah satu server sedang dalam keadaan mati atau maintenance.

Pada Ga mbar 6 ditunjukkan Setelah melakukan penginstalan freeNAS (Network Attached Storage), lakukan konfigurasi Storage NFS pada proxmox untuk penggabungan freeNAS dengan proxmox 


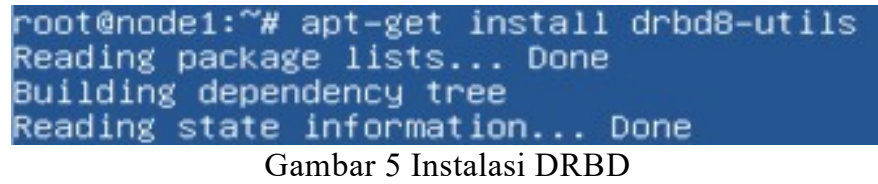

Edit: NFS

ID:

Sever:

Export:

Content:

linda

10.42.42.51

/mnt/yourstorage/jails

Disk image, Container $t$

Gambar 6 Konfigurasi Storage NAS

Tahapan perancangan High Availability:

1) Membuat group HA, untuk penggabungan ketiga cluster.

2) Memasukkan vm ID yang akan dimasukkan kedalam group HA.

3) Melakukan migrasi vm kepada ketiga cluster.

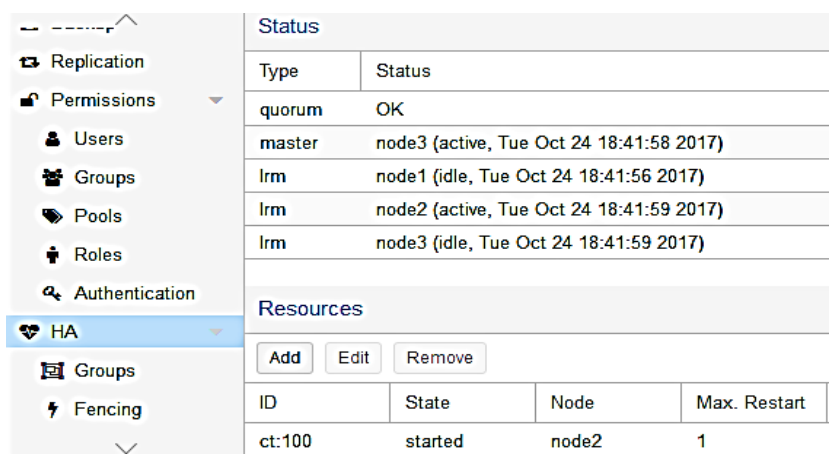

Gambar 7 Perancangan High Availability

Perancangan layanan ketersediaan tinggi yang bertujuan membantu perpindahan mesin virtual disaat salah satu server sedang mati.

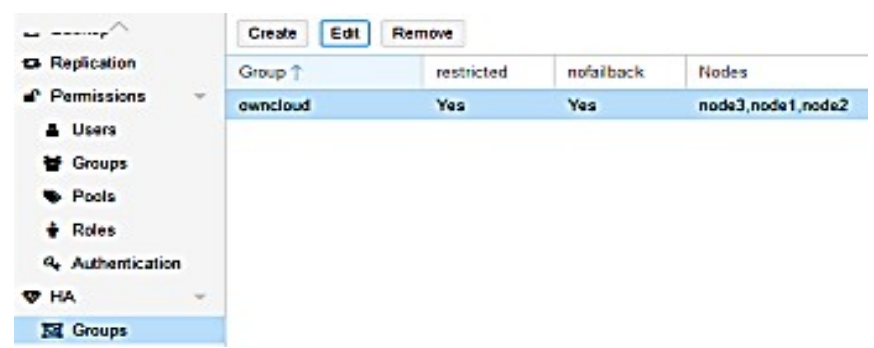

Gambar 8 Pengelompokan server HA

Pengelompokan server yang diberikan ketersediaan layanan tinggi untuk sistem backup pada mesin virtual agar bisa selalu diakses.

(a)

(b)
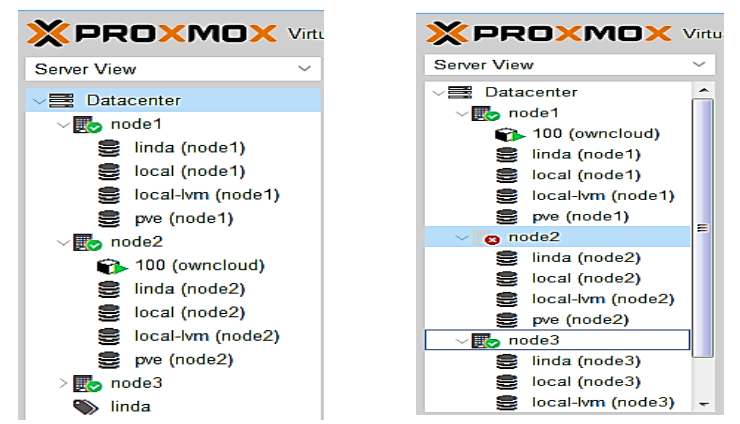

Gambar 9 Perpindahan Mesin Virtual Owncloud
Dari gambar diatas menjelaskan tahap cara kerja High Availability (HA) pada sistem cluster, berikut adalah penjelasannya:

Tahapan awal, cloud yang akan diakses terdapat di server node 2 , dan tahap $b$ menjelaskan ketika server node 2 dimatikan, maka owncloud akan berpindah ke server lainnya dalam keadaan yang stabil.

Tabel 3

Perpindahan Virtual Server

\begin{tabular}{|c|c|c|c|c|c|}
\hline No & Node & \multicolumn{3}{|c|}{$\begin{array}{c}\text { Waktu } \\
\text { Migrasi (s) }\end{array}$} & Rata-rata \\
\cline { 3 - 6 } & & 1 & 2 & 3 & \\
\hline 1 & Node 1 ke Node 2 & 10 & 9 & 10 & 9.7 \\
\hline 2 & Node 2 ke Node 3 & 4 & 4 & 3 & 3.7 \\
\hline 3 & Node 3 ke Node 1 & 3 & 3 & 3 & 3 \\
\hline
\end{tabular}

Berdasarkan pengkuran waktu pada migrasi saat jalur aktif terputus, pengkuran waktu migrasi dilakukan pada server 1 menuju server 2, lalu dari s erver 2 menuju server 3 dan dimigrasikan kembali ke server 1.

Tabel 4

Infrastruktur as a Service

\begin{tabular}{|c|c|c|c|c|}
\hline No & $\begin{array}{c}\text { Ukuran } \\
\text { File (KB) }\end{array}$ & CPU & Memory & $\begin{array}{c}\text { Network } \\
\text { Traffic (s) }\end{array}$ \\
\hline 100 & 164.1 & $2.1 \%$ & $185.2 \mathrm{Mb}$ & $46.45 \mathrm{~Kb}$ \\
\hline 100 & 2915 & $8.18 \%$ & $215.02 \mathrm{Mb}$ & $58.06 \mathrm{~Kb}$ \\
\hline
\end{tabular}

Berdasarkan penggunaan Infrastruktur pada vm 100 (owncloud) yang terletak pada node1. Uji coba pemasukkan file sebesar $164.1 \mathrm{~Kb}$ dan $2915 \mathrm{~Kb}$ pada owncloud, maka hasil dari penggunaan kinerja pada CPU, Memory dan Network Traffic sesuai dengan tabel diatas.

$$
\text { Tabel } 5
$$

Penggunaan Kapasitas Node

\begin{tabular}{|c|c|c|c|c|c|c|}
\hline N & $\begin{array}{c}\text { CPU } \\
\text { Delay }\end{array}$ & $\begin{array}{c}\text { CPU } \\
\text { Usage }\end{array}$ & $\begin{array}{c}\text { Server } \\
\text { Load }\end{array}$ & Memory & $\begin{array}{c}\text { Kapasitas } \\
\text { Memory }\end{array}$ & $\begin{array}{c}\text { Network } \\
\text { Traffic (s) }\end{array}$ \\
\hline n1 & $\begin{array}{c}\mathbf{6 8 . 7 9} \\
\%\end{array}$ & $\mathbf{9 . 6 5 \%}$ & $\mathbf{3 . 4 3}$ & $\mathbf{1 . 0 1 G b}$ & $\mathbf{2 2 \%}$ & $\mathbf{1 0 . 7 3 \mathrm { MB } / \mathbf { s }}$ \\
\hline n2 & $\begin{array}{c}\mathbf{2 2 . 1 6} \\
\%\end{array}$ & $\mathbf{5 . 2 4 \%}$ & $\mathbf{0 . 6 4}$ & $\mathbf{1 . 0 1 G b}$ & $\mathbf{2 5 \%}$ & $4.31 \mathrm{Mb} / \mathbf{s}$ \\
\hline n3 & $\begin{array}{c}\mathbf{2 . 6 6} \\
\%\end{array}$ & $\mathbf{6 . 4 6 \%}$ & $\mathbf{0 . 7}$ & $\mathbf{7 1 5 . 2 2 \mathrm { Mb }}$ & $\mathbf{3 5 \%}$ & $\mathbf{2 1 . 5 8 \mathrm { Kb } / \mathbf { s }}$ \\
\hline
\end{tabular}

Berdasarkan penggunaan CPU ketiga node ketika server sedang bekerja. Terdapat perubahan pada masing masing diagram di server.

Tabel 6 Pengukuran Downtime

\begin{tabular}{|c|c|c|c|}
\hline No & IP Address & Status & Waktu $(\mathrm{ms})$ \\
\hline 1 & $10.42 .42 .55($ Node 1$)$ & Alive & $0.58 \mathrm{~ms}$ \\
\hline 2 & $10.42 .42 .56($ Node 2$)$ & Alive & $0.02 \mathrm{~ms}$ \\
\hline 3 & 10.42 .42 .57 (Node3) & Alive & $0.02 \mathrm{~ms}$ \\
\hline
\end{tabular}

Pengukuran waktu pengkuruan downtime pada saat migrasi dilakukan, terlihat hasil sesuai pada tabel pada saat uji elapsed time on return packets menggunakan Fping.

\section{KESIMPULAN DAN SARAN}

Berdasarkan hasil pengujian dapat diambil beberapa kesimpulan. Hasil dari implementasi sistem cluster yang menggunakan metode High Availability yang didukung oleh lingkup DRBD mampu memberikan waktu migrasi dan downtime yang sangat rendah pada server 2 dan 3 . Berbeda dengan server 1 yang tidak diberikan konfigurasi DRBD yang 
mendapatkan waktu migrasi dan downtime yang lebih tinggi yaitu dengan rata-rata 9.7 (s) untuk waktu migrasi dan $0.58 \mathrm{~ms}$ untuk waktu downtime. Dengan adanya resource yang tinggi, mampu mengurangi downtime yang terlalu lama pada server. Dapat disimpulkan waktu migrasi dari server 1 ke server lainnya sebanyak rata-rata 9.7 second pada node1 ke node2. Lalu didapatkan rata-rata waktu migrasi $3.7 \mathrm{~s}$ econd dari node 2 ke node 3 dan rata-rata 3 second dari node 3 kembali ke node1. Dengan waktu downtime $0.58 \mathrm{~ms}$ pada node1, $0.02 \mathrm{~ms}$ pada node 2 dan 0.02 ms pada node 3 .

\section{DAFTAR PUSTAKA}

[1] Yud i Restu Adi, Oki Dwi Nurhayati, Eko Didik Widianto "Perancangan Sistem Cluster Server Untuk Jaminan Ketersediaan Layanan Tinggi Pada Lingkungan Virtual", JNTETI, Vol. 5, No. 2, Mei 2016.

[2] Irfani, "Implementasi High Availability Server Dengan Teknik Failover Virtual Computer Cluster", http://eprints.ums.ac.id/35179/1/NASKAH\%20PUBLIK ASI.pdf.

[3] I Gede Putu Krisna Juliharta, Wayan Supedana, Dandy Pramana Hostiadi, " High Availability Web Server Berbasis Open Source Dengan Teknik Failover Clustering", Seminar Nasional Teknologi Informasi dan Multimedia 2015 STMIK AMIKOM Yogyakarta, 6-8 Februari 2015.

[4] Tadapaneni, N. R. (2018). Cloud Computing: Opportunities And Challenges. International Journal of Technical Research and Applications.

[5] Arief Arfriandi, "Perancangan, Implementasi, Dan Analisis Kinerja Virtualisasi Server Menggunakan Proxmox, Vmware Es x, Dan Openstack", JURTEK http://jurtek.akprind.ac.id/sites/default/files/182_192_A RIEF.pdf.

[6] Agni Isador Harsapranata, Ahmad Rais Ruli "Pemanfaatan Open Source Dalam Clustering Untuk Penerapan High Availability Pada Server”, Konferensi Nasional Ilmu Sosial \& Teknologi (KNiST) Maret 2017, pp. 132 136.

[7] Sugeng Purwantoro E.S.G.S, Muhammad Arief Fadhly, "Distributed Replicated Block Device (DRBD) Sebagai Alternatif High Availability Data Rep licat ion Pada Cloud Computing", Jurnal Politeknik Caltex Riau http://jurnal.pcr.ac.id.

[8] A. Kovari, P. Dukan, "KVM \& Open VZ virtualization based IaaS Open Source Cloud Virtualization Platforms: OpenNode, Proxmox VE", College of Dunaújváros/Institute of Informatics, Dunaújváros, Hungary, http://ieeexplore.iee.org/document/6339540/.

[9] Muhammad Hafiz Zidni, “ Cloud Storage Dengan Implementasi Network Attached Storage Metode Cluster Pada Server Virtual",

[10] Chauhan, S., \& Vermani, S. (2016). Shift from Cloud Computing to Fog Computing. Journal of Applied Computing, $\quad 1(1), \quad 25-29$. 